J. Appl. Numer. Optim. 1 (2019), No. 3, pp. 347-362

Available online at http://jano.biemdas.com

https://doi.org/10.23952/jano.1.2019.3.11

\title{
A FRACTIONAL DERIVATIVE APPROACH TO MODELLING A SMART GRID-OFF CLUSTER OF HOUSES IN AN ISOLATED AREA
}

\author{
Didier Calogine*, Oanh Chau, Philippe Lauret \\ PIMENT, 117 rue du Général Ailleret, 97430 Le Tampon, La Réunion, France
}

\begin{abstract}
This paper presents an operational model of an electrical power supply in order to meet the load of a cluster of houses in a remote mountainous area. In outlying areas, an isolated power network represents the most economical solution. However, the implementation of a cluster of houses in an electrical microgrid requires optimal management of the power supply-demand in order to reach the users' requirements. Our case study is located in the "Cirque de Mafate" in Reunion Island. To build the model, the different types of individual consumption and the available energy production in situ are described. Energy management is achieved through a large mixed integer linear programming system. The model allows the production to fit the consumption by minimizing losses. Numerical calculations have been performed in order to determine an optimal solution that minimizes the use of the battery energy storage system and also satisfies the comfort of the inhabitants. The use of fractional derivative is introduced in the battery storage model. Simulations show that this emerging technology may lead to a technical solution that meets the above requirements of battery energy use and consumer satisfaction. It is also shown that a most effective and efficient use of energy resources is required in order to achieve sustainable management of electrical energy.
\end{abstract}

Keywords. Off-grid microgrid; Mixed integer linear programming; Demand-side management; Optimization; Fractional-order model.

\section{INTRODUCTION}

The commonly-named "Cirque de Mafate" in French, located in Reunion island (a French Overseas Department in the Indian Ocean), is a caldera, which is a large crater like a depression that has been formed following the evacuation of a magma chamber. It was formed from the collapse of the large shield volcano named the "Piton des Neiges". The name "Mafate" comes from

\footnotetext{
${ }^{*}$ Corresponding author.

E-mail addresses: dcalogin@univ-reunion.fr (D. Calogine), oanh.chau@univ-reunion.fr (O. Chau), philippe.lauret@ univ-reunion.fr (P. Lauret).

Received January 14, 2019; Accepted August 5, 2019.
}

2019 Journal of Applied and Numerical Optimization 
the Malagasy word "Mahafaty", which means lethal, an allusion to the difficulty in accessing this place. This cirque is entirely enclosed by mountains, with tall cliffs, and considerable declivities. There are some flat lands, where a few hamlets are located (Fig. 1). In the $19^{\text {th }}$ century, the first inhabitants of this very inaccessible cirque were the "Maroon" which means slaves who escaped from their masters and who took refuge in the mountains. Later poor white labourers came to settle in these regions. A detailed description of the origins of Mafate, its geography, history, population and activities are given by Souffrin [1].

The cirque has several denoted villages such as "La Nouvelle", "Marla", "Roche-Plate", the "Îlet-aux-Orangers", etc. The Cirque is entirely the property of the local government.

These villages and hamlets have grocery stores, bars and restaurant services. Many inhabitants have opened tourist activities such as accommodation (Bed and Breakfasts).

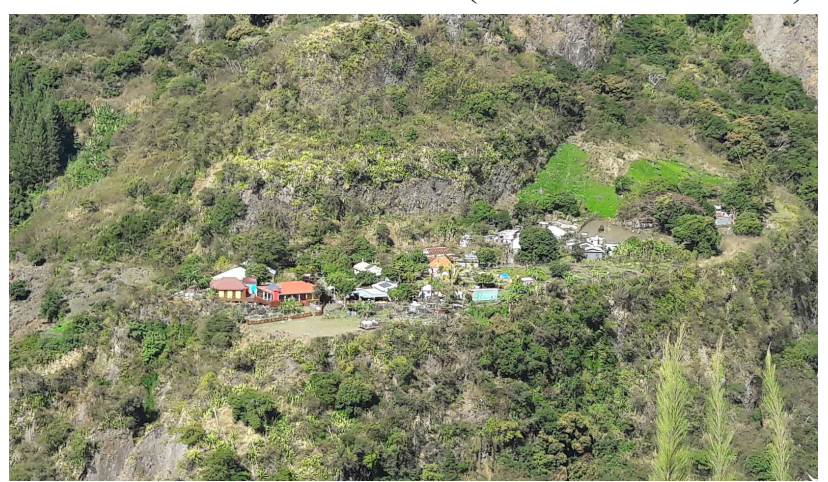

Figure 1. Example of a hamlet in the "Cirque de Mafate".

Here, there are no roads. All access, including supplies and emergencies, is by foot or by helicopter. There is no main supply of electricity. Inhabitants produce their own electricity using solar panels, with battery storage, and diesel generators as a back-up. However, fuel for the latter must be brought in by helicopter at a high cost. Because of the reduced available power supply, inhabitants systematically use low-consumption light bulbs. Similarly, all inhabitants use solar water heaters. Gas powered heat can supplement these devices but gas canisters must also be brought in by helicopter. As a consequence, renewable resources represent the only alternative for the survival of the residents in these mountains.

Individual power production for each house has existed in the Cirque de Mafate to date. However, the equipment is obsolete. Moreover, the storage devices are mainly based on lead-acid technology, which has proved little efficiency. A more successful management of the production and the consumption of energy is thus planned. Modelling tools allow the setup of optimisation methods for the implementation of a smart off-grid. Examples of planning and implementation of smartgrids are given by Gellings in [2]. A type of energy management system favouring both the participation and commitment of the inhabitants is also foreseen. The aim of the method is to control the consumption of electricity [3]. 
The remainder of this paper is as follows: a brief review of previous studies is presented in Section 2. In Section 3 the different typologies of electrical appliances in the cluster of houses are listed. Section 4 outlines the modelling, the resolution method of the nonlinear problem. Fractional calculus is employed in Section 5 to improve the flexibility of the optimal solution. Section 6 presents and explains the different simulation results. Finally, some conclusions and comments in Section 7 will conclude this paper.

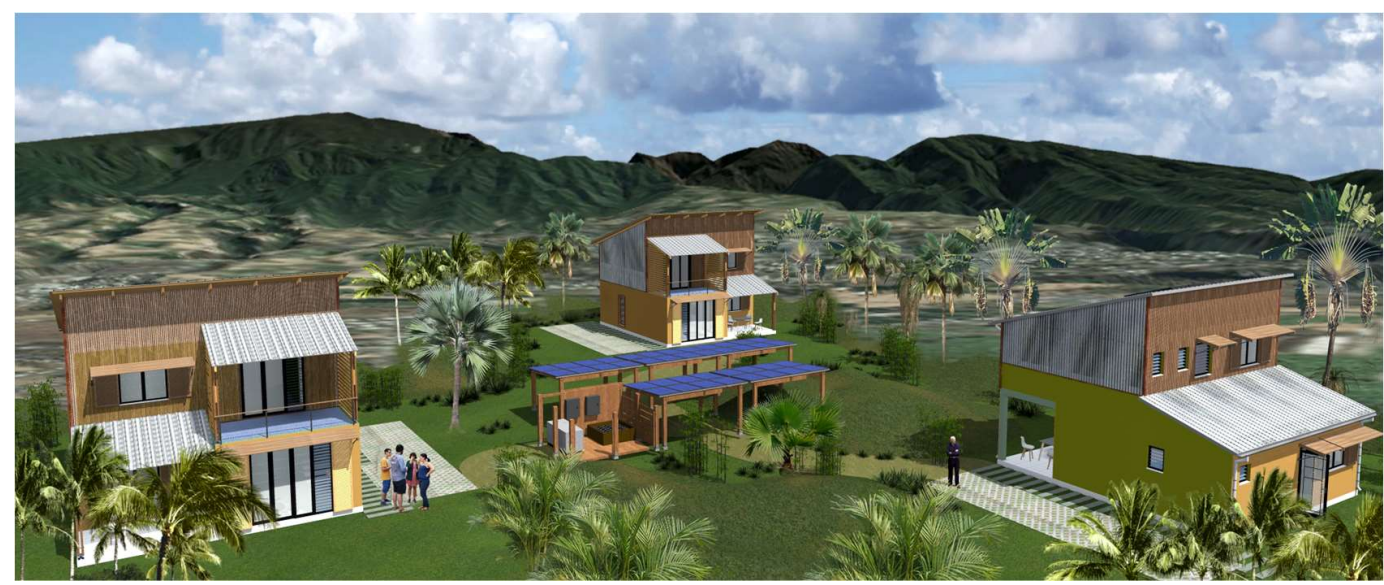

Figure 2. Design of the future microgrid of "Roche Plate".

\section{SURVEY OF PREVIOUS WORK}

The management of energy and electricity consumption in particular, currently represents one of the major issues of a decentralized microgrid. This optimal management of resources is obtained by a smart model based on users' trends [3]. This approach opens the way for a rational and sustainable exploitation of shared resources. Mathematical models were set up by previous studies to achieve this goal.

Several methods concerning microgrid management are given in the literature. Various mathematical models are used starting from linear to nonlinear formulation, from a deterministic to a stochastic point of view. These models are combined with specific numerical techniques to maintain the optimal microgrid working point.

A deterministic model setup by Ha et al. $[4,5]$ results in an integer linear programming problem (PLNE). Solving this problem gives ranges of use for devices throughout one full day, depending on weather conditions and electricity prices. In Le et al. [6] authors also took into account uncertainty related to the prediction model of resources.

In this article, a model based on Ha et al. is set up in a case study of 3 microgrid houses with collected data in situ. The method proposed in $[4,5]$ is applied and formulae are modified for our study case. In addition, this work focuses on a new formulation for the storage management which is the key to improving the reliability of the microgrid.

The new formulation introduced in the paper is based on fractional calculus [7]. This 
mathematical tool allows us to model real electric elements that are obviously not ideal. Taking into account the memory effect in modelling, a new electrical circuit occurred. More precisely, they include memresistive, memcapacitative and meminductive. In recent studies, the relationship between memcapacity and fractional calculus has been highlighted [8]. As the permittivity of several dielectrics changes specifically according to magnetic field intensity, the current flowing across the capacity has to be modelled by a nonlinear function. These devices, namely nanoscale capacitors, are characterized by a hysteresis dependence of applied voltage that causes memory effect. These so-called "fractional order devices" introduce a non-integer order system for currentvoltage relation.

In the field of energy storage, models that involve fractional electrical circuits are used for Lithium-ion batteries $[11,12]$. Starting with the relationship between voltage and the current of the capacitor in fractional order condition [8,13], a fractal capacitor is defined to take the fractal dimension of the porous structure of the electrode into account. The nonlinearity characteristics of the distribution of charge on electrodes over time are then modelled by fractional calculus. The fractional-order capacitive element is characterized by its fractional order $\alpha$ and the pseudo capacitance $C_{\alpha}$. This represents a constant phase element denoted CPE [15]. A Warburg element could also be employed in series with a charge transfer resistance to obtain several orders of fractional circuit models. These circuits are classically presented in series, in cascade assembly or in a tree-like scheme to model diffusion behaviour $[15,16]$.

This fractional order behaviour of devices will be explored in this paper because these systems will certainly have a future in energy storage.

\section{PRoblem STATEMENT}

In this section, the description of the configuration of the study is given. A microgrid on the site of "Roche Plate" for three neighbouring houses is planned in this work (Fig. 2). These houses present different typologies: two of them concern families with 1 or 2 children, the third one is a cottage offering 3 rooms to accommodate possible hikers and trekkers. An inventory of the electrical devices was carried out in situ to measure the daily consumption of the users. This consumption is summed up in Table 1 [9].

With regard to the location and the lifestyle of the inhabitants, individual electricity needs are relatively low. Indeed, houses are equipped with essential and necessary installations. However, to ensure the comfort of tourists, house $\mathrm{n}^{\circ} 1$ (the cottage) consumes much more than the two others. In this case, the proposed mix of housing seems to be favourable because the different levels of consumption can become complementary. By compensating for the use of energy during a 24 hour period, the autonomy of the microgrid becomes attainable. Some electric devices will then be deferrable using a time lag i.e. energy demand that can be displaced throughout the day to find a more convenient time slot for their utilization. 
Table 1

Characteristics of electrical devices.

\begin{tabular}{|c|c|c|c|c|}
\hline & Devices & Power (W) & Quantity & Usage (h/day) \\
\hline \multirow{9}{*}{$\begin{array}{l}- \\
\dot{0} \\
Z \\
0 \\
0 \\
\stackrel{0}{I}\end{array}$} & Light / Lamp & 15 & 5 & 1 to 6 \\
\hline & Laptop & 80 & 1 & 4 \\
\hline & $\begin{array}{c}\text { Portable radio } \\
\text { set }\end{array}$ & 25 & 1 & 2 \\
\hline & TV set & 150 & 3 & 1 to 5 \\
\hline & Freezer & 200 & 2 & - \\
\hline & Fridge & 200 & 2 & - \\
\hline & $\mathrm{Hi}-\mathrm{Fi}$ & 500 & 1 & 0.5 \\
\hline & Light / Lamp & 15 & 1 & 1 \\
\hline & $\begin{array}{l}\text { Washing } \\
\text { machine }\end{array}$ & 500 & 1 & 2 \\
\hline \multirow{9}{*}{ 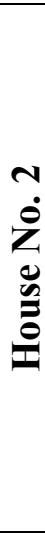 } & Light / Lamp & 15 & 1 & 2 to 3 \\
\hline & Light / Lamp & 5 & 5 & 1 \\
\hline & $\begin{array}{c}\text { Portable radio } \\
\text { set }\end{array}$ & 25 & 2 & 2 \\
\hline & TV set & 90 & 1 & 3 \\
\hline & Freezer & 200 & 2 & - \\
\hline & Fridge & 200 & 2 & - \\
\hline & Light / Lamp & 5 & 2 & 0.1 to 3 \\
\hline & Light / Lamp & 15 & 2 & 1 \\
\hline & $\begin{array}{l}\text { Washing } \\
\text { machine }\end{array}$ & 500 & 1 & 0.5 \\
\hline \multirow{8}{*}{ 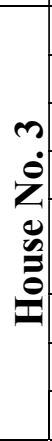 } & TV set & 90 & 1 & 3 \\
\hline & Light / Lamp & 15 & 5 & 1 to 3 \\
\hline & Freezer & 200 & 2 & - \\
\hline & Fridge & 200 & 2 & - \\
\hline & $\begin{array}{l}\text { Washing } \\
\text { machine }\end{array}$ & 500 & 1 & 0.1 \\
\hline & Light / Lamp & 15 & 1 & 2 \\
\hline & DVD player & 80 & 1 & 0.2 \\
\hline & Laptop & 80 & 1 & 0.2 \\
\hline
\end{tabular}

One of the aims of our project is to update the production device with efficient photovoltaic panels. A recent panel producing more that $300 \mathrm{~W} /$ unit is then proposed. The yield of this monocristallin solar panel is more than $20 \%$. At the moment these panels present the best qualityprice ratio. Concerning the storage device, batteries with lithium technology show a better efficiency and lifetime than those that are currently in operation. The state of charge for LithiumIon battery varies from $20 \%\left(S O C_{\min }\right)$ to $80 \%\left(S O C_{\max }\right)$ during our simulations. To satisfy the 
continuity of curves as a cyclic scheme, the initialisation of the $S O C$ parameter is given at 1 am in the morning with a value of approximately $45 \%$.

The local solar resources are also evaluated. Bird's model is used in the first step to model the clear sky solar irradiance (Fig. 3). In the future, as a second step, a set of on-site measurements will be carried out to assess the local solar resources.

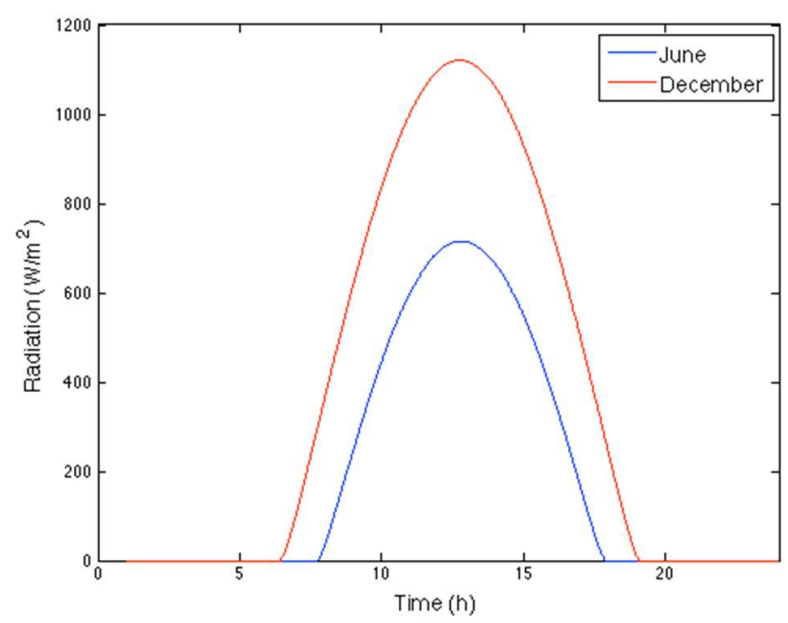

Figure 3. Predicted hourly solar radiation for a summer month (December) and a winter month (June).

Having defined the parameters of production and storage, the optimal management of the microgrid by taking into account the flexibilities of the use of the energy during the 24 hour period, is set up. The optimization problem that follows can then be formulated as a mixed nonlinear programming problem.

\section{MATHEMATICAL MODEL}

In this section, the exact consumption of each electrical device is given during a period of $T$ hours [4]. Typically $T=24$ hours for one day ( the time step $\Delta t=1$ hour). For this period, the time interval $[k, k+1]$ is defined for $1 \leq k \leq T$ in the cluster of three houses $(\mathrm{T}+1$ represents the $1^{\text {st }}$ hour due to the periodicity of the day). The problem is formulated in the same way as an optimization problem with constraints [5,6]. A formula for the objective function to be minimized is then established. The corresponding list of parameters is defined by the following notations.

If $f_{j}(i)$ denotes the end of the consumption $i$ in the house $j, f_{j}^{\min }(i)$ and $f_{j}^{\max }(i)$ refer to the lower and upper bound of $f_{j}(i)$ (Table 2). $f_{j}^{o p t}(i)$ is the optimal value corresponding to the resident's wish of end of the consumption $i$ in the house $j$. The evaluation of $U_{j}(i)$, the distance between $f_{j}(i)$ and $f_{j}^{o p t}(i)$, is proposed. This positive quantity will be reduced to the possible minimum in order to greatly satisfy the user's comfort. Starting by: 


$$
f_{j}^{\min }(i) \leq f_{j}(i) \leq f_{j}^{\max }(i)
$$

$U_{j}(i)$ the distance between $f_{j}(i)$ and $f_{j}^{o p t}(i)$ is defined by:

$$
U_{j}(i)=\left\{\begin{array}{lll}
\frac{f_{j}(i)-f_{j}^{o p t}(i)}{f_{j}^{m a x}(i)-f_{j}^{o p t}(i)} & \text { if } & f_{j}(i)>f_{j}^{o p t}(i) \\
\frac{f_{j}^{o p t}(i)-f_{j}(i)}{f_{j}^{o p t}(i)-f_{j}^{m i n}(i)} & \text { if } & f_{j}(i) \leq f_{j}^{o p t}(i)
\end{array}\right.
$$

Table 2

\begin{tabular}{|c|c|c|c|c|c|c|}
\hline & Device $j$ & $\begin{array}{l}f_{j}^{\min } \\
\text { (h) }\end{array}$ & $f_{j}^{o p t}(h)$ & $f_{j}^{\max }(\mathrm{h})$ & Duration (h) & $\begin{array}{c}\text { Deferrabl } \\
e\end{array}$ \\
\hline \multirow{9}{*}{ 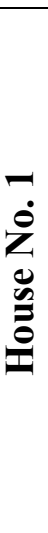 } & Light / Lamp & 1 & 23 & 24 & 6 & No \\
\hline & Laptop & 1 & 23 & 24 & 2 & No \\
\hline & $\begin{array}{c}\text { Portable radio } \\
\text { set }\end{array}$ & 1 & 23 & 24 & 2 & No \\
\hline & TV set & 1 & 23 & 24 & 1 & No \\
\hline & Freezer & 1 & 23 & 24 & 24 & No \\
\hline & Fridge & 1 & 23 & 24 & 24 & No \\
\hline & $\mathrm{Hi}-\mathrm{Fi}$ & 9 & 16 & 17 & 0,5 & Yes \\
\hline & Light / Lamp & 1 & 23 & 24 & 1 & Yes \\
\hline & $\begin{array}{l}\text { Washing } \\
\text { machine }\end{array}$ & 14 & 18 & 19 & 2 & Yes \\
\hline \multirow{9}{*}{ 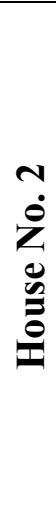 } & Light / Lamp & 5 & 6 & 23 & 3 & No \\
\hline & Light / Lamp & 5 & 6 & 23 & 2 & No \\
\hline & $\begin{array}{c}\text { Portable radio } \\
\text { set }\end{array}$ & 5 & 19 & 23 & 2 & No \\
\hline & TV set & 5 & 18 & 23 & 3 & No \\
\hline & Freezer & 1 & 23 & 24 & 24 & No \\
\hline & Fridge & 1 & 23 & 24 & 24 & $\mathrm{No}$ \\
\hline & Light / Lamp & 5 & 19 & 23 & 2 & Yes \\
\hline & Light / Lamp & 5 & 19 & 23 & 1 & Yes \\
\hline & $\begin{array}{l}\text { Washing } \\
\text { machine }\end{array}$ & 9 & 10 & 17 & 1 & Yes \\
\hline \multirow{8}{*}{ 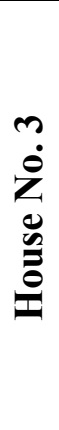 } & TV set & 5 & 6 & 23 & 3 & No \\
\hline & Light / Lamp & 5 & 6 & 23 & 2 & No \\
\hline & Freezer & 1 & 23 & 24 & 24 & No \\
\hline & Fridge & 1 & 23 & 24 & 24 & No \\
\hline & $\begin{array}{l}\text { Washing } \\
\text { machine }\end{array}$ & 8 & 9 & 19 & 1 & Yes \\
\hline & Light / Lamp & 5 & 19 & 23 & 3 & Yes \\
\hline & DVD player & 14 & 19 & 23 & 1 & Yes \\
\hline & Laptop & 14 & 16 & 23 & 1 & Yes \\
\hline
\end{tabular}

Modelling parameters of electrical appliances. 
It is easy to verify that $0 \leq U_{j}(i) \leq 1$, and the fact that $U_{j}(i)$ is closer to 0 means that the user is more satisfied. The last formula (Eq. (2)) can be written simply by:

$$
U_{j}(i)=\delta_{j_{u}}(i) * \frac{f_{j}^{o p t}(i)-f_{j}(i)}{f_{j}^{o p t}(i)-f_{j}^{m i n}(i)}+\left(1-\delta_{j_{u}}(i)\right) * \frac{f_{j}(i)-f_{j}^{o p t}(i)}{f_{j}^{m a x}(i)-f_{j}^{o p t}(i)},
$$

where $\delta j_{u}(i) \in\{0 ; 1\}$ is a binary variable defined by:

$$
\delta_{j_{u}}(i)=\mathbf{1} \text { if and only if } f_{j}(i) \leq f_{j}^{o p t}(i) .
$$

Finally, Eq. (3) is written in the form:

$$
\begin{aligned}
U_{j}(i)= & \left(\frac{f_{j}^{o p t}(i)}{f_{j}^{o p t}(i)-f_{j}^{\min }(i)}+\frac{f_{j}^{o p t}(i)}{f_{j}^{m a x}(i)-f_{j}^{o p t}(i)}\right) * \delta_{j_{u}}(i) \\
& -\left(\frac{1}{f_{j}^{o p t}(i)-f_{j}^{\text {min }}(i)}+\frac{1}{f_{j}^{m a x}(i)-f_{j}^{o p t}(i)}\right) * z_{j_{u}}(i)+\frac{f_{j}(i)-f_{j}^{o p t}(i)}{f_{j}^{m a x}(i)-f_{j}^{o p t}(i)},
\end{aligned}
$$

where

$$
\boldsymbol{z}_{\boldsymbol{j}_{u}}(\boldsymbol{i})=\boldsymbol{\delta}_{\boldsymbol{j}_{u}}(\boldsymbol{i}) * \boldsymbol{f}_{\boldsymbol{j}}(\boldsymbol{i})
$$

Consequently, the objective function to be minimized is given by:

$$
J\left(U_{1}, \ldots, U_{n b}, P_{B_{-} o u t}\right)=\sum_{k=1}^{T} P_{B_{-} \text {out }}(k) *\left(1-\delta_{p v}(k)\right)+\sum_{j=1}^{n b} \sum_{i=1}^{I_{j}} U_{j}(i)
$$

with $I_{j}$ the number of electrical appliances in the house $\mathrm{n}^{\circ} j$, for $j$ going from $l$ to the number $n b$ of houses. The symbol $\delta_{p v}(k) \in\{0 ; 1\}$ denotes a logical variable defined by $\delta_{p v}(k)=1$ if solar radiation is non zero.

The minimisation problem can be formulated as follows:

$$
\text { Problem : } \quad \underset{\boldsymbol{U}_{1}, \ldots, \boldsymbol{U}_{\boldsymbol{n} b}, \boldsymbol{P}_{\boldsymbol{B}_{-} \text {out }}}{\operatorname{Arg} \min } J\left(\boldsymbol{U}_{\mathbf{1}}, \ldots, \boldsymbol{U}_{\boldsymbol{n} \boldsymbol{b}}, \boldsymbol{P}_{\boldsymbol{B}_{-} \text {out }}\right)
$$

During the range time $[k * \Delta t,(k+1) * \Delta t], P_{B_{-} o u t}(k)$ is the energy supplied by the battery. This term has to be minimized in the absence of solar radiation to ensure the longevity of the energy storage. When $t$ denotes for each instant (hour), $1 \leq t \leq T$, the balance for the supply power is,

$$
\boldsymbol{P}_{P V}(\boldsymbol{t})+\boldsymbol{P}_{B_{-} \text {out }}(\boldsymbol{t}) \geq \boldsymbol{P}_{\text {Load }}(\boldsymbol{t})+\boldsymbol{P}_{B_{-} \text {in }}(\boldsymbol{t}),
$$

where $P_{B_{-} \text {in }}$ is the power stored in the battery and $P_{B_{-} \text {out }}$ the power supplied by it, $P_{\text {Load }}$ is the energy consumed by the electric devices, $P_{P V}$ the energy produced by the photovoltaic panel.

This problem is linearized following the procedure described by Bemporad et al. [10]. The method used introduces some new variables and constraints and their additional systems of inequalities [5,6]. The Mixed Integer Linear Programing formulation (MILP) is then solved to obtain the assignment of services throughout the day.

In the following section, a new formulation of the management of the state of charge (SOC) is proposed using the fractional derivative technique. The state of charge of the battery represents 
the remaining power available in the microgrid, which is the main parameter for the battery management system. A better evaluation and prediction of this parameter enables us to prolong the lifetime of the storage system which is the most expensive device in the microgrid. The SOC parameter fluctuates following the electrical charge transfer in circuit. This transport of charge is driven by $P_{B_{-} \text {in }}$ and $P_{B_{-} \text {out }}$ parameters.

\section{FRACTIONAL SOC MODEL OF ENERGY STORAGE}

The SOC of storage units represents the strategic parameter for an effective management of the microgrid. Let us recall that using the method of coulomb counting [11], the SOC represents the remaining capacity of battery with respect to the nominal capacity (or rated capacity). The following equation demonstrates its time variation:

$$
\operatorname{soC}(\boldsymbol{t})=S O C_{0}+\int_{0}^{t} \frac{I(s)}{C_{n}} d s,
$$

where the $S O C_{0}$ is the initial value, $I$ the load current and $C_{n}$ the nominal capacity. The discretisation of the previous equation using the sampling $\Delta t$ can be written as follows:

$$
\boldsymbol{S O C}(\boldsymbol{t}+\Delta t)=\boldsymbol{S O C}(\boldsymbol{t})+\frac{\boldsymbol{I}(t) * \Delta t}{\boldsymbol{C}_{n}} .
$$

The concept proposed in this paper is to use capacitors with memory for energy storage.

From here, a nonlinear model is employed. Then a fractional relationship between current and voltage can be deduced in the form $[8,13]$ :

$$
I(t)=\frac{d^{\alpha} \boldsymbol{q}(t)}{d t^{\alpha}}=\frac{d^{\alpha}\left(\boldsymbol{C}_{f} * \boldsymbol{v}(\boldsymbol{t})\right)}{d t^{\alpha}},
$$

where $v(t)$ is the terminal voltage of the capacitor and $C_{f}$ the fractional capacity. The main benefit of this tool consists in modelling the history of the recorded data of the physical parameter unlike classical derivation that is restricted to fixed and local fluctuation.

Let us introduce the mathematical formula of fractional derivative according to the GrünaldLetnikov definition (GL fractional derivative) [7, 17], i.e.

$$
D^{\alpha} \boldsymbol{v}(t)=\lim _{\Delta t \rightarrow 0} \frac{1}{\Delta t^{\alpha}} \sum_{j=0}^{\left[\frac{t-a}{\Delta t}\right]}(-1)^{j} *\left(\begin{array}{c}
\alpha \\
j
\end{array}\right) * \boldsymbol{f}(\boldsymbol{t}-\boldsymbol{j} \cdot \Delta t),
$$

with $a, t$ are the bounds of the operation and

$$
\left(\begin{array}{l}
\alpha \\
j
\end{array}\right)= \begin{cases}1 & \text { if } j=0 ; \\
\frac{\alpha(\alpha-1) * \ldots *(\alpha-(j-1))}{j !}=\frac{\Gamma(\alpha+1)}{\Gamma(j+1) * \Gamma(\alpha-j+1)} & \text { if } j>0,\end{cases}
$$

where the gamma function is $\Gamma(\alpha)=\int_{0}^{\infty} \xi^{\alpha-1} e^{-\xi} d \xi$. The computation of this particular derivative requires all the passed values of $v(t)$ i.e. its history. Consequently, it represents a non-local operator.

The evolution equation of the fractional state of charge is given by:

$$
\frac{d}{d t}\left(\boldsymbol{S O C}_{f}\right)=\frac{d^{\alpha}}{d t^{\alpha}}\left(\frac{C_{f}}{C_{n}} *\left(\boldsymbol{v}_{\boldsymbol{B}_{-} \text {in }}(t)-\boldsymbol{v}_{\boldsymbol{B}_{-} \boldsymbol{o u t}}(t)\right)\right) .
$$


where $v_{B_{-} \text {in }}(t)$ and $v_{B_{-} \text {out }}(t)$ refer to the voltage drop of fractional capacitor in the charge and discharge mode respectively, $\Delta t$ the time step and $C_{n}$ the rate capacity of the battery. These terms take into account the charging efficiency, the capacity of the battery, charging and discharging power. $S O C_{f}(t)$ denotes the state of charge of the battery at $t$. Limit bounds for the state of charge $S O C_{f}^{\min }$ and $S O C_{f}^{\max }$ are introduced to restrict the variation width of the SOC's battery at $t$ in the MILP problem.

The discretised form of the equation (14) to be implemented in the optimal problem is given by:

$\operatorname{sOC}(t+\Delta t)=\operatorname{SOC}(t)+$

$\Delta t^{(1-\alpha)} \sum_{j=0}^{\left[\frac{t-a}{\Delta t}\right]}(-1)^{j} * \frac{C_{f}}{C_{n}} * \frac{\Gamma(\alpha+1)}{\Gamma(j+1) * \Gamma(\alpha-j+1)} *\left(\boldsymbol{v}_{\boldsymbol{B}_{-} \text {in }}(\boldsymbol{t}-j \cdot \Delta t)-\boldsymbol{v}_{\boldsymbol{B}_{-} \boldsymbol{o u t}}(\boldsymbol{t}-j \cdot \Delta t)\right)$.

Thus, the use of fractional derivative allows us to take the memory of the physical system into account. Due to the presence of fractional derivative, the computing time obviously increases [18]. $C_{f}$ parameter is the fractal capacity of unit. This needs to be defined by experimental studies. In this first approach it can be regarded as a constant.

\section{SIMULATION RESULTS}

For the setup of the microgrid, the photovoltaic production is estimated by Bird's model (Fig. 3). Experimental measures in situ will refine the demand-side management of the microgrid. Based on the residents' requirements (Table 1), the optimal operating point of the microgrid was obtained [19]. Indeed, the distribution of loads during a period of 24 hours is obtained for each house taking the objective function into account (Eq. 7). The results are presented in the following figures.

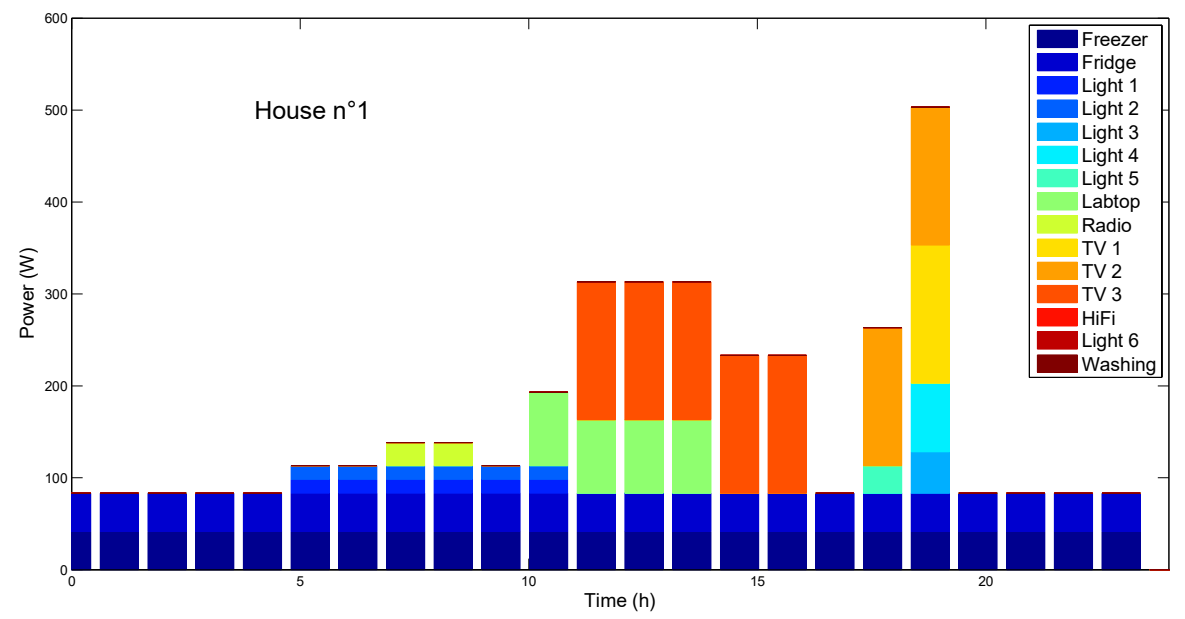



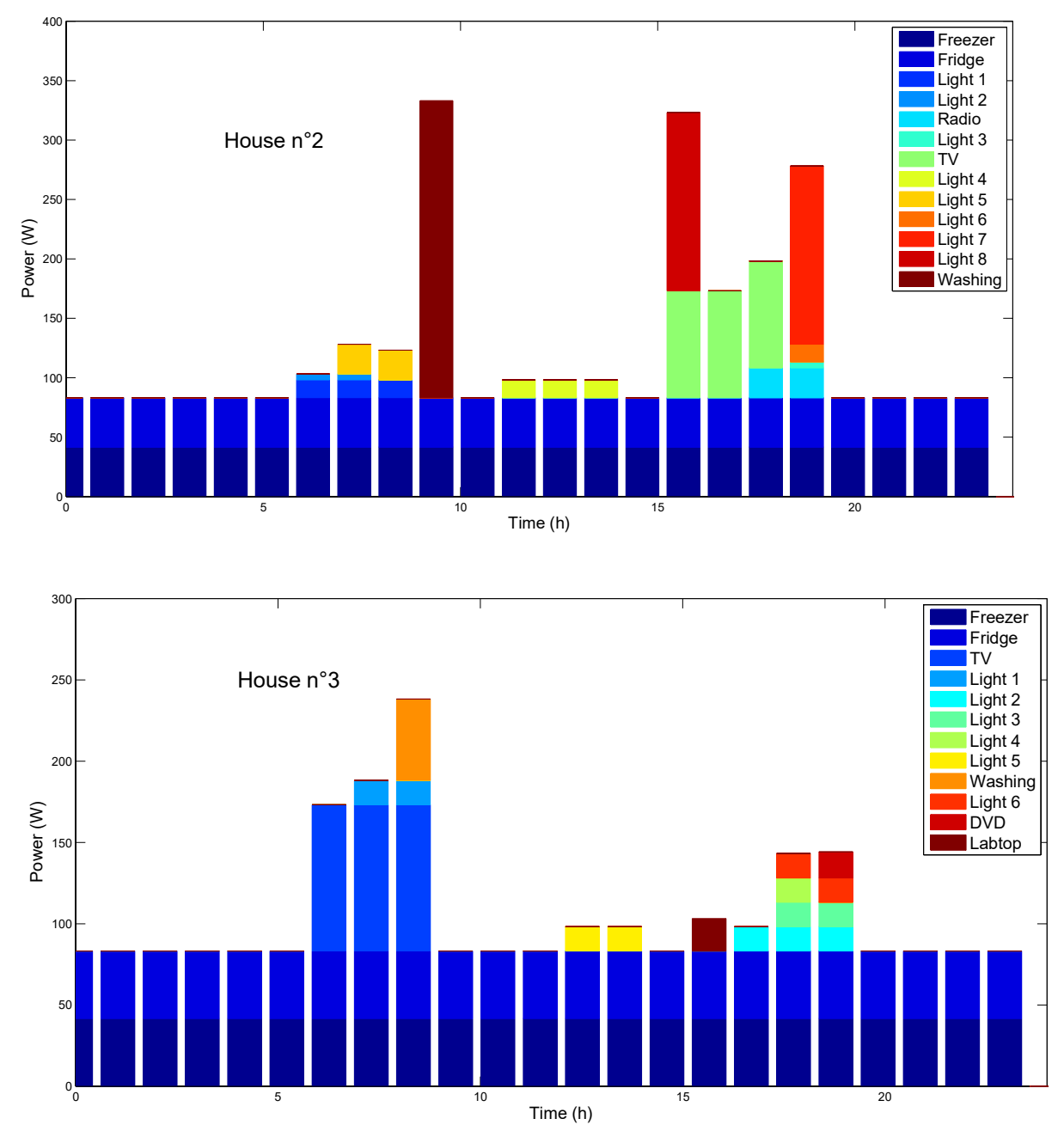

Figure 4. Sequence of the electrical appliances in the three houses.

(a) House $n^{\circ} 1$. (b) House $n^{\circ} 2$. (c) House $n^{\circ} 3$.

Figure 4 shows the characterized presence of permanent consumption for a full 24 hour period, due to the activity of refrigerators and freezers. As for the punctual loads, these are localized at the beginning of the day, from 5 am until the evening. Indeed, this configuration presented here corresponds to the optimal distribution of service proposed by the solver. When it was possible, an effort was made by the solver to return loads in the solar radiation zone in order to minimise power flows, as shown in Figure 4. 

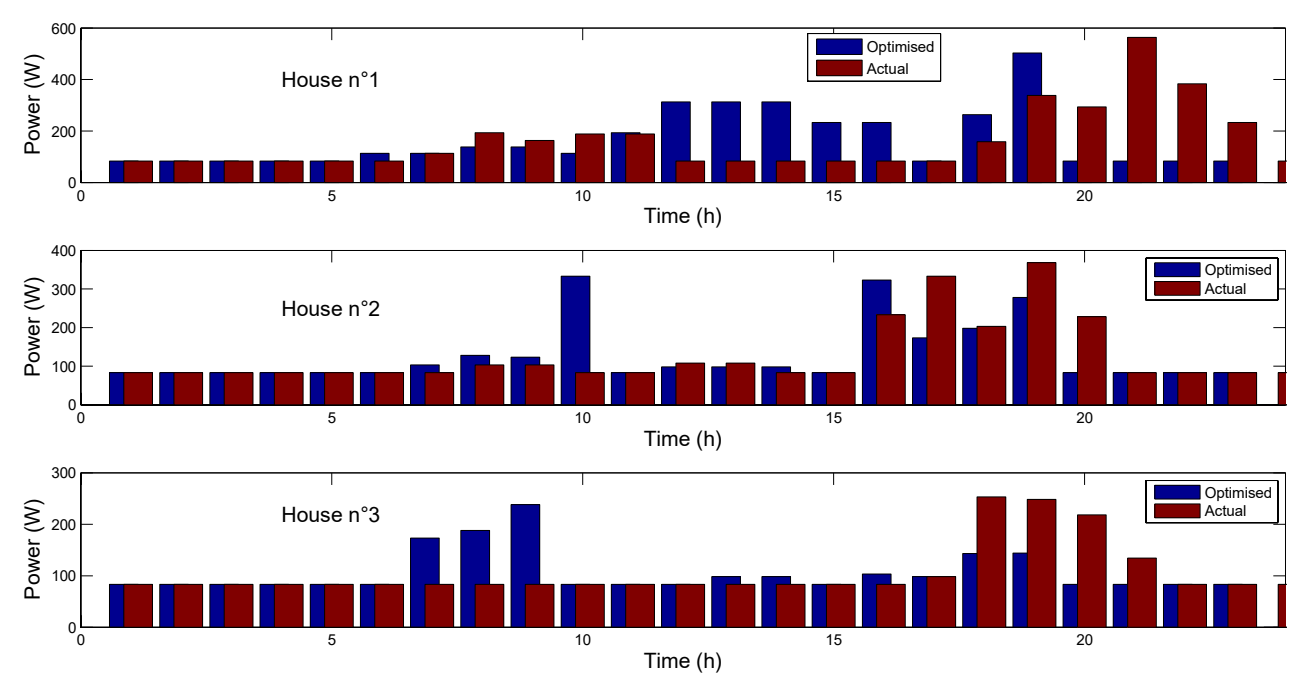

Figure 5. Daily electrical consumptions of houses in different configuration.

In Figure 5 the confrontation of the classical use of devices and recommended use is presented. The effect of time lag is observed. The presence of the residual load before the rising sun and after sunset penalizes the optimal score of the solver. The high solicitation of the load at the end of the day represents the major challenge for the model of demand-side management.
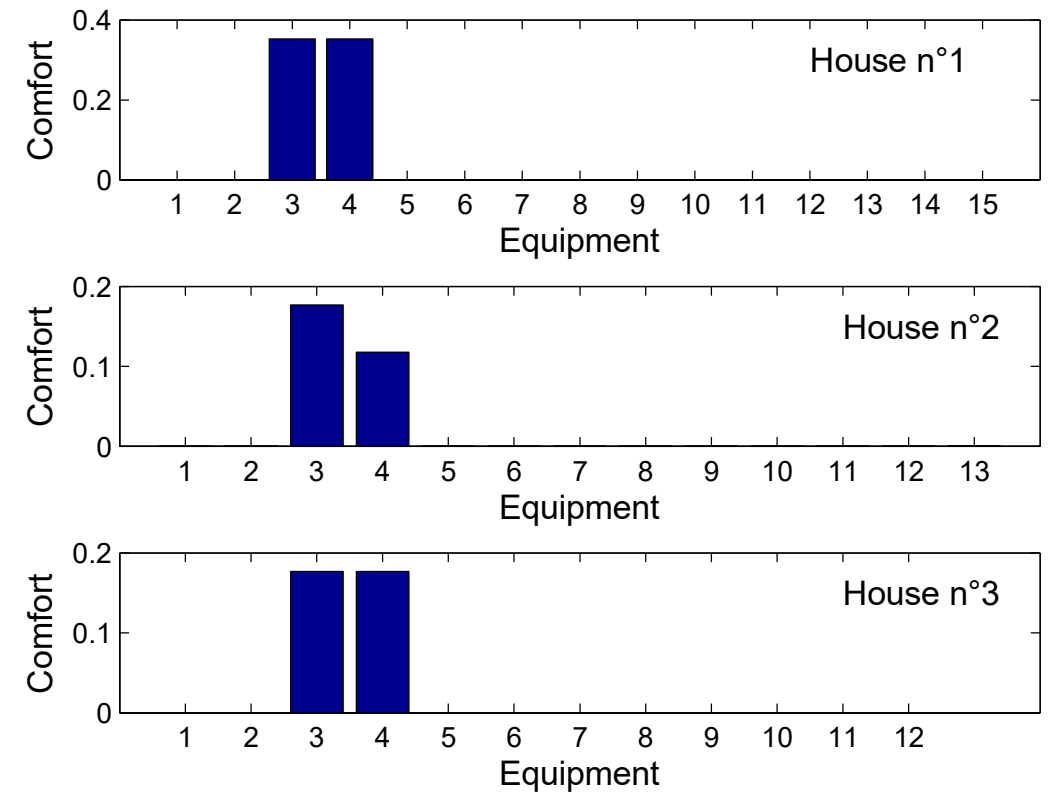

Figure 6. Evaluation of users' comfort $\left(\mathrm{U}_{\mathrm{j}}\right)$ for each piece of equipment.

For the comfort of the user, the satisfaction defines the optimal time service obtained by the algorithm and the desired time from users (Eq. 5). Through our simulations a highest-level gap of $35 \%$ is observed for two devices in house $n^{\circ} 1$ and $n^{\circ} 3$ (see Fig. 6). This allows us to validate the 
configuration of the proposed use of services. In our case study, this result is obtained based on the constraints of the use of lighting at the beginning of the evening.
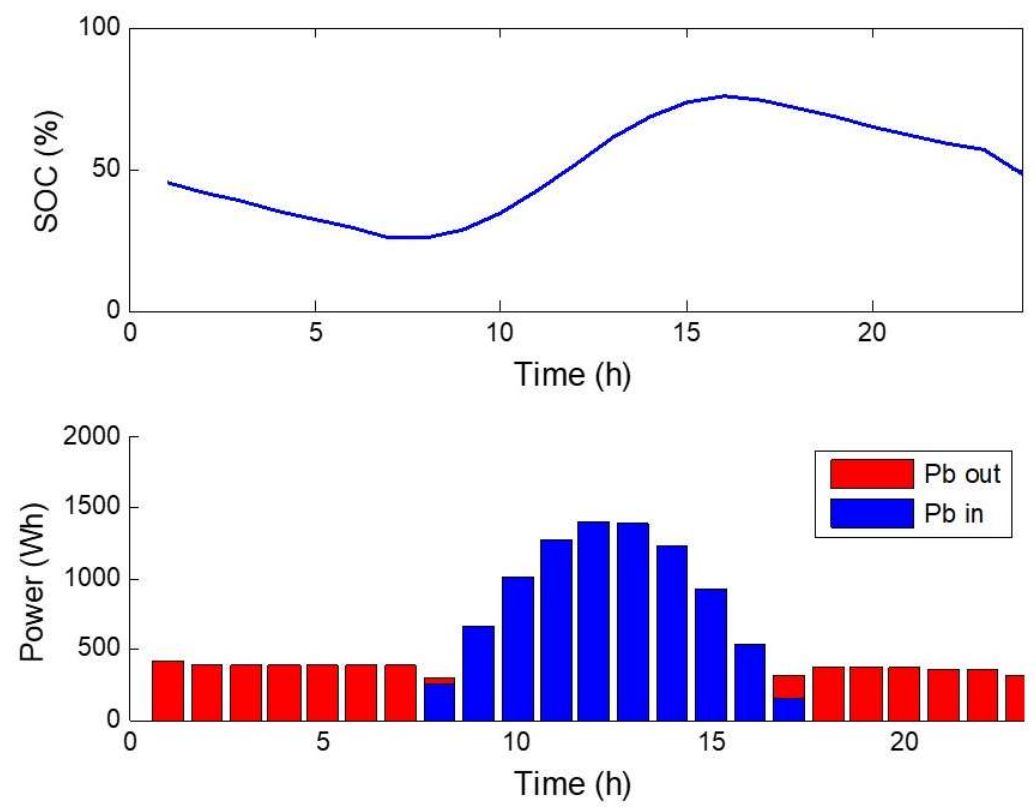

Figure 7. Variation of charge and transfer power for the battery.

In Figure 7, the evolution of the battery state of charge is represented. The graph allows users to follow the dynamics of flux exchanged between production and storage. Note that from 1 am until 7 am for the morning and from 6 pm until $12 \mathrm{pm}$ for the evening, the battery is mainly expected to supply the demand of fridges and freezers. An increase of this supplied power is observed from 8 am due to the early activity of users. At the end of the day, the same behaviour is reproduced with an outbreak of the power request to the battery $P_{B_{-} \text {out }}$ and afterwards this stabilized. The power $P_{B_{-} i n}$ stored in batteries logically follows the curve of photovoltaic production as represented in Figure 3.

Based on this first modelling of our microgrid, some further possible strategies for their management can be proposed. As an illustration, if the weather forecast for the following day is optimistic (clear sky) then the production of the entire day can be used for the demand. On the other hand, when this forecast becomes pessimistic the backup mode is activated i.e. the consumption for 3 days will be targeted. A share of the energy is then reserved at battery level for the following 2 days. The study of these strategies will be presented in a future paper. 


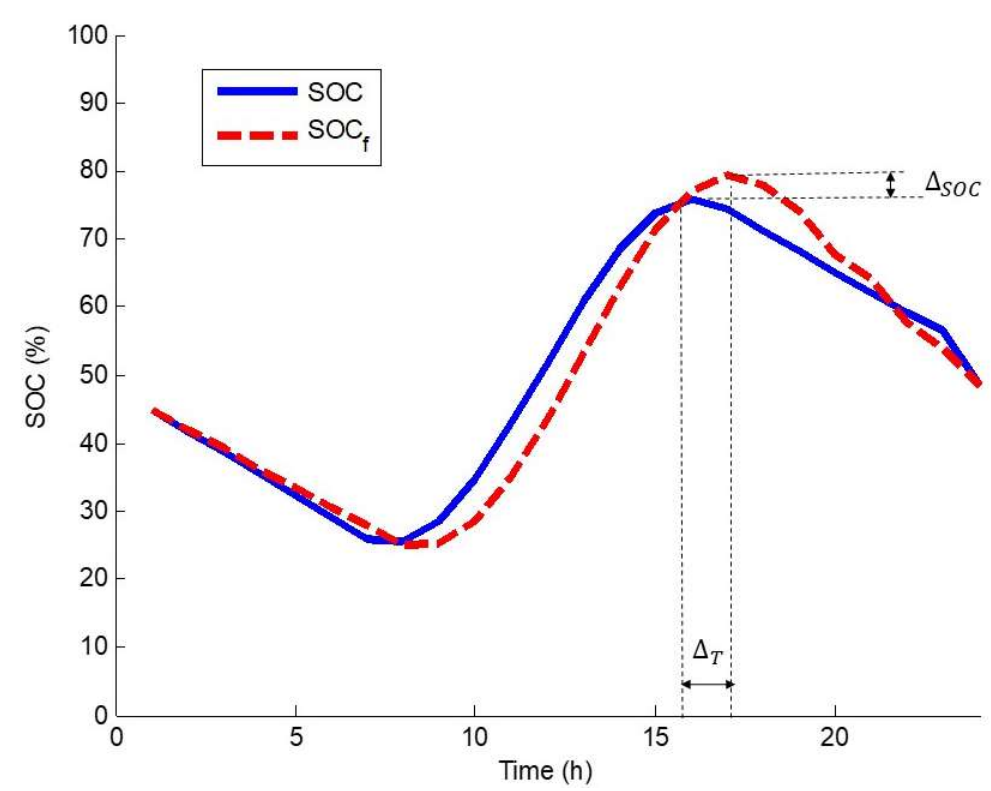

Figure 8. Variation of State of Charge models using classical and fractional derivative

In Figure 8, storage simulations have been performed with fractional derivative parameter $\alpha=$ 0.9 [12]. The graph shows that the fractional model variation (red dotted line) represents a slight delay with respect to the classical one (blue solid line). This delay creates a phase shift which enables us to extend the charge period by approximately 1 hour. As this charge period goes beyond the availability of the solar resources, a larger amount of energy is then made available at the end of the day. A greater charge amplitude $\Delta_{S O C}$ is also observed due to the presence of fractional order. Using fractional derivative in the simulation introduces a timing offset or phase adjustment in order to improve the model. The major rule of time step $\Delta_{T}$ is highlighted in the simulation. The range of $\Delta_{T}$ depends on the length of memory which has been taken into account. The memory frame needs to be significant enough to remove instability in the SOC variation. Regularity and continuity versus time is necessary to increase the unit's reliability. The existence of $\Delta_{T}$ in the $S O C$ variation provides more flexibility with regard to the constraints when the algorithm finds the optimal solution of the PLNE problem.

The strategy promoted to find the better solution seems to be more efficient using memory use. Fractional derivative enables us to look for an efficient overall solution and to manage the available energy sparingly. Even in the discharge mode, the method allows us to limit the decrease of the $S O C$ in order to anticipate future consumption for the day. Finally, the mathematical tool models the overall management of energy storage throughout the entire day.

The use of fractional circuit elements allows us to obtain the fractional performance of system. The fractal parameters that control memory effect need to be evaluated by an experimental test. The validation of a real time energy management system is to be implemented in the Mafate site.

\section{CONCLUSION}


Effective management of a cluster of houses is an alternative to obtain the most efficient use of natural energy resources. Looking for the minimal consumption of energy for one house is not enough to optimize photovoltaic production. At the scale of a house (nanogrid scale) the model must be upgraded to the level of a microgrid for a more efficient use of resources. The main advantage of the production and the participative consumption is that it enables a flexible use of almost all electrical appliances. This merging of service offers more adaptability to renegotiate delivery or load-shedding. The clustering of houses enables autonomy to be reached in the electricity network.

A fractional approach was proposed for the management of energy during the daytime. Using electrical units with memory, the variation of the battery's $S O C$ underscores a possible curve shift due to the memory effect of storage. This effect represents one alternative to confront the peak of energy demand observed every day in the early evening. The use of fractional solution is particularly efficient if the autonomy of the microgrid over a three-day period is examined. Then, overall optimisation through a non-local operator is necessary to reach this goal.

Concerning future studies, a hierarchical priority for the load is envisaged in case of low solar resources. A stochastic modelling of the management of the microgrid is in progress to take into account uncertainties in the forecasting of resources and the demand for electrical power. Improvements of this model will be implemented on an experimental prototype in situ.

\section{Acknowledgements}

This paper was introduced within the framework of the "Micro Reseau Mafate" project, which was financially supported by the European Regional Development Fund (FEDER in French). We are thankful to our colleague (Edel Lynch) who provided expertise that greatly assisted the drafting of this paper and the union SIDELEC for the data on "Roche Plate" microgrid.

\section{REFERENCES}

[1] E. Souffrin, Ethno-histoire, appropriation et possession de la terre dans le cirque de Mafate, île de La Réunion, Université de Nice-Sophia Antipolis, 1992.

[2] C. W. Gellings, Smart Grid Planning and Implementation, Taylor \& Francis Group, 2015.

[3] G. Foggia, Pilotage Optimal de Système Multi-sources pour le Bâtiment, Institut National Polytechnique de Grenoble- INPG, 2009.

[4] D. L. Ha, Un système avancé de gestion d'énergie dans le bâtiment pour coordonner production et consommation. Modélisation et simulation. PhD thesis, Électronique, Électrotechnique, Automatique, Traitement du Signal. Institut National Polytechnique de Grenoble, 2007.

[5] D. L. Ha, H. Joumaa, S. Ploix, M. Jacomino, An optimal approach for electrical management problem in dwellings, Energy and Buildings 45 (2012), 1-14.

[6] M. H. LE, Prise en compte des incertitudes de prédiction dans la gestion des flux d'énergie dans l'habitat. Institute National Polytechnique de Grenoble - INPG, 2011.

[7] K.B. Oldham, J. Spanier, The Fractional Calculus, Academic Press, New York, 1974.

[8] I. Petras, Y. Chen, Fractional-order circuit elements with memory, 13th International Carpathian Control Conference, 552-558, 2012. 
[9] T. Reunion, Programme d'electrification rurale par installations photovoltaiques autonomes avec stockage batterie, 2015.

[10] A. Bemporad, M. Morari, Control of systems integrating logic, dynamics and constraints, Automatica 35 (1998), 407- 427.

[11] S. Yang, C. Deng, Y. Zhang, Y. He, State of Charge estimation for Lithium-Ion battery with a temperature compensated model, Energies, 10 (2017), 1560-1574.

[12] H. Mu, R. Xiong, H. Zheng, Y. Chang, Z. Chen, A novel fractional order model based state-of-charge estimation method for lithium-ion battery, Appl. Energy 207 (2017), 384-393.

[13] A.M. Movahhed, H.T. Shandiz, S.K.H. Sani, Comparison of fractional order modelling and integer order modelling of fractional order buck converter in continuous condition mode operation, Adv. Eelectrical Electronic Eng. 14 (2016), 531-542.

[14] X. Lu, H. Li, J. Xu, S. Chen, N. Chen, Rapid estimation method for state of charge of Lithium-Ion battery based on fractional continual variable order model, Energies 11 (2018), 714.

[15] C. Zou, L. Zhang, X. Hu, Z. Wang, T. Wik, M. Pecht, A review of fractional-order techniques applied to lithiumion batteries, lead-acid batteries and supercapacitors, J. Power Sources, 390 (2018), 286-296.

[16] H. Kanoun, J.D. Gabano, T. Poinot, Fractional modeling of ultracapacitors dynamic behavior, IFAC Proceedings Volumes 18th IFAC World Congress, 44 (2011), 13978-13983.

[17] Y. Jiang, B. Xia, X. Zhao, T. Nguyen, C. Mi, R.A. de Callafon, Identification of fractional differential models for Lithium-ion polymer battery dynamics, IFAC-PapersOnLine, 50 (2017), 405-410.

[18] D. Baleanu, K. Diethelm, E. Scalas, J. J. Trujillo, Fractional Calculus: Models and Numerical Methods, pp. 1016. World Scientific, Singapore, 2012.

[19] P. Esquirol, P. Lopez, L'ordonnancement, Economica, Paris, 1999. 